\title{
Euplocania Enderlein: description of the female of E. quinquedivisa Silva-Neto, García Aldrete \& Rafael (Psocodea, 'Psocoptera', Ptiloneuridae), with a checklist of Euplocania species in Brazil
}

\author{
Karen de Araújo Barroso ${ }^{1,3}$; Alberto Moreira da Silva-Neto ${ }^{1,4}$; Alfonso Neri García Aldrete ${ }^{2,5}$ \& José Albertino Rafael ${ }^{1,6}$ \\ 1 Instituto Nacional de Pesquisas da Amazônia (INPA), Coordenação de Pesquisas em Entomologia (CPEN), \\ Programa de Pós-Graduação em Entomologia. Manaus, AM, Brasil. \\ 2 Universidad Nacional Autónoma de México (UNAM), Instituto de Biología, Departamento de Zoología, \\ Laboratorio de Entomología. México, D.F., México. \\ ${ }^{3}$ ORCID: http://orcid.org/0000-0001-7785-9129. E-mail: karen.kab@outlook.com \\ ${ }^{4}$ ORCID: http://orcid.org/0000-0002-4522-3756. E-mail: bio.alberto@gmail.com (corresponding author) \\ ${ }^{5}$ ORCID: http://orcid.org/0000-0001-7214-7966. E-mail: anga@ib.unam.mx \\ ${ }^{6}$ ORCID: http://orcid.org/0000-0002-0170-0514. E-mail: jarafael@inpa.gov.br
}

Abstract. The unknown female of Euplocania quinquedivisa Silva-Neto, García Aldrete \& Rafael, is described and illustrated. Information on sexes known and distribution in Brazilian states is included for the known species of Brazilian Euplocania.

Key-Words. Taxonomy; Neotropics; Epipsocetae.

\section{INTRODUCTION}

Euplocania Enderlein (1910) is one of 12 recent genera in the psocopteran family Ptiloneuridae. It presently includes forty-seven described species, with twenty-six species known only from males, four species known only from females, and seventeen species known from both sexes; these species occur in Nicaragua, Colombia, Peru, Brazil, Ecuador and Paraguay (Silva-Neto et al., 2019). Brazil is the second-most rich country for Euplocania species, with fifteen species distributed in five Brazilian States. Only two of these species have the female described (Table 1). Euplocania quinquedivisa Silva-Neto, García Aldrete \& Rafael was described on basis of a male specimen collected in a Malaise trap set 18 meters from the ground, in a tower located in Reserva ZF2, inside the Amazonian forest in the Brazilian state of Amazonas. This species could not be assigned in any of the species-groups proposed by García Aldrete et al. (2013), so SilvaNeto et al. (2019) created the species-group quinquedivisa to include it. One of us (KAB) recently found in a miscellany of insects preserved in $80 \%$ ethanol, at the Instituto Nacional de Pesquisas da Amazônia, in Manaus, Amazonas, Brazil (INPA), a male specimen of E. quinquedivisa (Fig. 1) and a female specimen (Fig. 2) associated with it, which was assigned as the unknown female of this species. The purpose of this paper is to describe and illustrate the female of $E$. quinquedivisa, to present an update of the diagnosis this species, including female characters, and to provide a checklist of Euplocania species in Brazil.

\section{MATERIAL AND METHODS}

1 male and 1 female were available for study. All specimens were collected through Malaise traps in five different heights (ground level, $8 \mathrm{~m}$ above ground level, $16 \mathrm{~m}, 24 \mathrm{~m}$ and $32 \mathrm{~m}$ ) on a tower located in the Amazonian forest, in an area owned by the Reserva Biológica do Cueiras (ZF-2). They were dissected in $80 \%$ ethanol, and their parts were mounted on permanent slides in Canada balsam. Standard measurements (in $\mu \mathrm{m}$ ), were taken with a filar micrometer. Abbreviations of parts measured are as follows: FW and HW: right fore- and hindwing lengths; $F, T, t 1, t 2$ and $t 3$ : lengths of femur, tibia and tarsomeres 1,2 and 3 of right hind leg; $f 1 . . . f n$ : lengths of flagellomeres 1 ...n of right antenna; $M \times 4$ : length of fourth segment of right maxillary palpus; IO: minimum distance between compound eyes in dorsal view of head; $\mathrm{D}$ and $\mathrm{d}$ : antero-posterior and transverse 
Table 1. Brazilian species of Euplocania, sexes known, species group, general distribution and distribution in Brazilian States (between parentheses).

\begin{tabular}{|c|c|c|c|}
\hline Species & Sexes known & Species group & Distribution \\
\hline E. ariasi Vinasco-Mondragón, González \& García Aldrete & Male & amabilis & Brazil (Goiás) \\
\hline E. badonneli New \& Thornton & Both & amabilis & Brazil (Rondônia), Colombia, Peru \\
\hline E. bujariensis Silva-Neto, García Aldrete \& Rafael & Male & amabilis & Brazil (Acre) \\
\hline E. cearaensis Silva-Neto, García Aldrete \& Rafael & Male & amabilis & Brazil (Ceará) \\
\hline E. cerata New & Both & cerata & Brazil (Amazonas), Peru \\
\hline E. equorum Vinasco-Mondragón, González \& García Aldrete & Male & amabilis & Brazil (Pará) \\
\hline E. hutchingsi Silva-Neto, García Aldrete \& Rafael & Male & amabilis & Brazil (Acre) \\
\hline E. manausensis Vinasco-Mondragón, González \& García Aldrete & Male & amabilis & Brazil (Amazonas) \\
\hline E. picta New & Male & amabilis & Brazil (Amazonas) \\
\hline E. pseudopictaoides Silva-Neto, García Aldrete \& Rafael & Male & amabilis & Brazil (Acre) \\
\hline E. quinquedivisa Silva-Neto, García Aldrete \& Rafael & Both & quinquedivisa & Brazil (Amazonas) \\
\hline E. rafaeli Vinasco-Mondragón, González \& García Aldrete & Male & amabilis & Brazil (Paraná) \\
\hline E. tocantina Mondragón, González \& García Aldrete & Male & amabilis & Brazil (Pará) \\
\hline E. uariniensis Silva-Neto, García Aldrete \& Rafael & Male & marginata & Brazil (Amazonas) \\
\hline E. xavieri Silva-Neto, García Aldrete \& Rafael & Male & amabilis & Brazil (Amazonas) \\
\hline
\end{tabular}

diameter, respectively, of right compound eye in dorsal view of head; PO: $d$ /D. The specimens were stored in " $C D$ boxes" as described by Silva-Neto et al. (2016).

Photographs of parts of the specimens were taken with a Leica DFC500 digital camera attached to a Leica M205C stereomicroscope, connected to a computer with the Leica Application Suite LAS V3.6 software, which includes an Auto-Montage module (Syncroscopy software). The distribution map was generated on the website SimpleMappr.

The specimens studied are deposited in the Invertebrate Collection of the Instituto Nacional de Pesquisas da Amazônia, Manaus, Amazonas, Brazil (INPA).

\section{RESULTS}

\section{Euplocania quinquedivisa Silva-Neto, García Aldrete \& Rafael (Figs. 1-10)}

Euplocania quinquedivisa Silva-Neto, García Aldrete \& Rafael, 2019: 383, Figs. 31-38.

Updated diagnosis: Hypandrium of five sclerites; forewings with a slender, pigmented marginal band, from pterostigma to $A_{2}$, with two hyaline areas, almost triangular, from $\mathrm{R}_{2+3}$ to CuP, on each side of the vein ends at wing margin. Ninth sternum broad, trapeziform, with three distinct areas, posteriorly with sides converging towards a membranous apex. Gonapophyses with v1 long, slender, heavily sclerotized; v2+3 stout, with short, blunt ended heel, with six setae on v3.

\section{Description}

Male: As described by Silva-Neto et al. (2019).

Female: Color: Compound eyes black, ocelli hyaline, with ochre centripetal crescents, head pattern (Fig. 3).
Scape proximally pale yellow, distally dark brown, pedicel yellow with a V-shaped spot dark brown, f1 proximally pale brown and then pale yellow, $\mathrm{f} 2$ pale yellow. Legs with coxae brown, trochanters dark brown, femora proximally dark brown, then brown; tibiae brown with apex dark brown; tarsomere 1 brown, distally dark brown, tarsomeres 2-3 yellow. Forewings veins brown, with a pigmented marginal band, from pterostigma to $A_{2}$, with two hyaline areas, almost triangular, from $R_{2+3}$ to CuP, on each side of the vein ends at wing margin Rs and crossvein Rs-M dark brown. Pterostigma dark brown with small irregular brown areas (Fig. 4). Hindwings (Fig. 5), almost hyaline, with a dark brown spot, between CuP and wing margin, a dark brown spot between $A_{1}$ and wing margin, veins brown, each with a brown spot distally at wing margin on $\mathrm{R}_{4+5}$ and $\mathrm{M}$.

Morphology: Compound eyes without interommatidial setae (Fig. 3). Outer cusp of lacinial tips broad, with six denticles (Fig. 6). Forewing pterostigma triangular, wider in the middle, narrow basally, areola postica tall, wide, with round apex, triangular, $M$ stem slightly concave proximally, then almost straight, with four primary branches (Fig. 4). Hindwing Rs and $\mathrm{R}_{2+3}$ straight, $\mathrm{R}_{4+5}$ almost straight, M sinuous (Fig. 5). Subgenital plate broad, wide basally, with sides converging towards a straight posterior border, pigmented area wide, V-shaped, setae as illustrated (Fig. 7). Ninth sternum (Fig. 8) broad, trapeziform, with three distinct areas, an anterior area narrow, with sinuous margins, a mesal area with two V-shaped subareas on each side, a posterior area anteriorly wide, posteriorly with sides converging towards a membranous apex, with two pairs of sub-areas: a lateral pair, wide in the middle, narrowing towards apex, longitudinally strongly sclerotized at anterior half; each pair connected horizontally by a narrow concave bridge; a mesal pair, small, lanceolate; underneath the mesal pair is located the gonopore, formed by a pair of arched sutures. Gonapophyses with v1 long, slender, heavily sclerotized; $v 2+3$ stout, wide proximally, with short, blunt 
ended heel; six setae on v3 as illustrated, distal process slender, acuminate, with a field of microsetae (Fig. 9). Epiproct triangular, with three mesal setae, other setae as illustrated (Fig. 10). Paraprocts almost triangular, broad, sensory fields with 27 trichobothria on basal rosettes; setae as illustrated (Fig. 10).

Measurements (in microns): FW: 5040, HW: 3274, F: 1329, T: 2197, t1: 914, t2: 93, t3: 126, f1: 1172, Mx4: 342, IO: 542, D: 467, d: 339, PO: 0.73.

Material examined: 1 male (INPA). BRAZIL. Amazonas Reserva ZF2, km 14, Torre. $02^{\circ} 35^{\prime} 21^{\prime \prime} \mathrm{S}, 60^{\circ} 06^{\prime} 55^{\prime \prime} \mathrm{W}$. 14.vi.03.vii.2018. Malaise trap, $16 \mathrm{~m}$ at the tower. Collection bottle in the west position. J.A. Rafael. 1 female (INPA). Same data as the male, except 19. ix.-03.x. 2017. Malaise trap, $8 \mathrm{~m}$ at the tower.

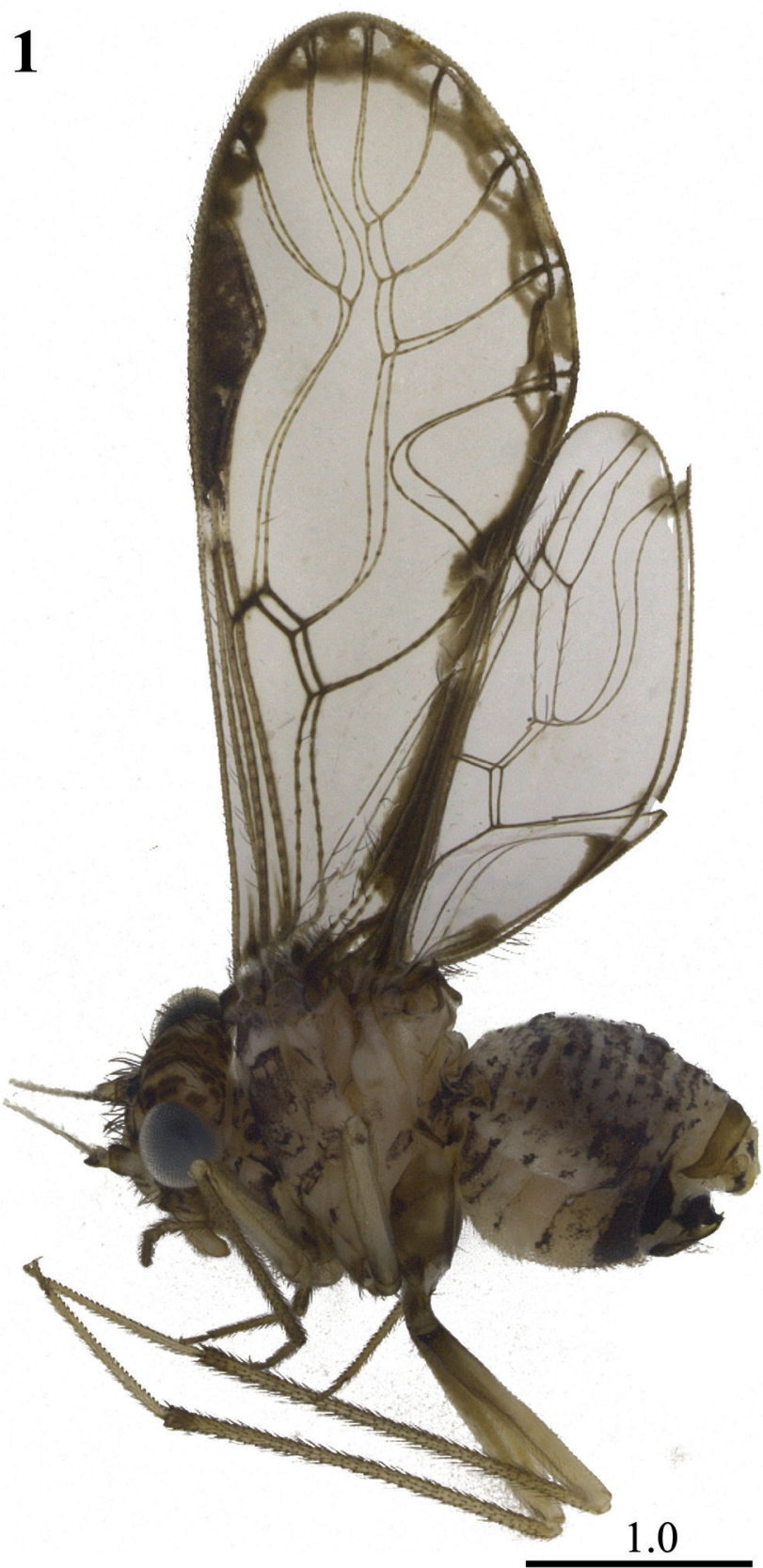

Figure 1. Euplocania quinquedivisa. Male. Scale in mm.

\section{DISCUSSION}

Brazil is divided in 26 states and a Federal District. Euplocania species occur in only seven of these Brazilian states (Table 1) and these species range from the south (Paraná: São José dos Pinhais) to the north (Amazonas: Uarini) of Brazil, with a distance between those extremes of some $3.042 \mathrm{~km}$ (Fig. 11). The Northern region is the most diverse for Euplocania (twelve species) with the state of Amazonas including six species (Fig. 11).

Among the fifteen Brazilian species of Euplocania only E. badonneli New \& Thornton and E. cerata New have known females; with the description of the female of E. quinquedivisa this number is raised to three species.

Euplocania quinquedivisa is unique among the 47 known species of Euplocania, having a distinct slender, pigmented marginal band in the forewing, from pterostigma to $A_{2}$, with two almost triangular hyaline areas from $\mathrm{R}_{2+3}$ to Cup, on each side of the vein ends at wing margin. Other Euplocania species have these hyaline areas in the pigmented marginal band (mentioned above), but in elliptical ( $E$. andinoamazonica García Aldrete, Carrejo \& Panche; E. vallecaucana González, García Aldrete \& Carrejo; E. chami González, García Aldrete \& Carrejo; E. darwini Carrejo, García Aldrete \& González; E. enderleini García Aldrete, Panche \& González; E. gallegoi González, García Aldrete \& Carrejo; E. mockfordi González, Carrejo \& García Aldrete; E. pati-

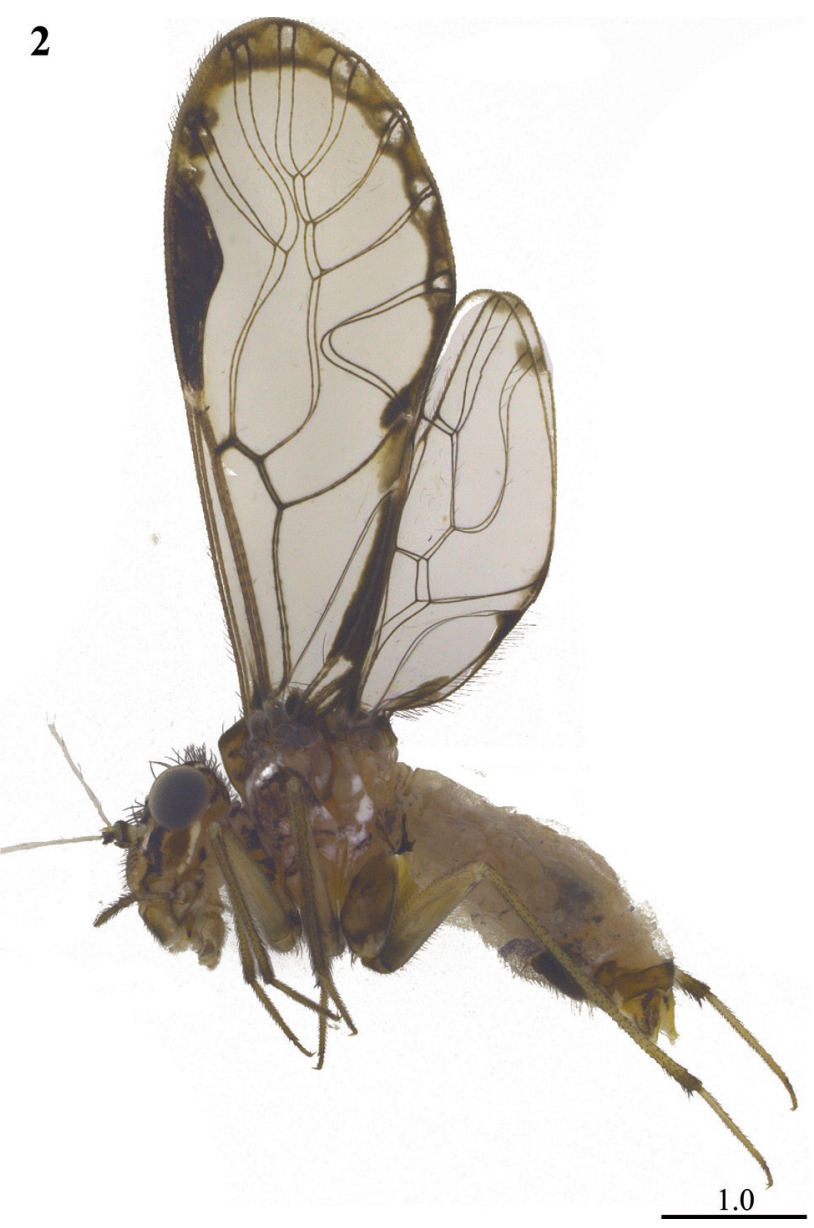

Figure 2. Euplocania quinquedivisa. Female. Scale in mm. 

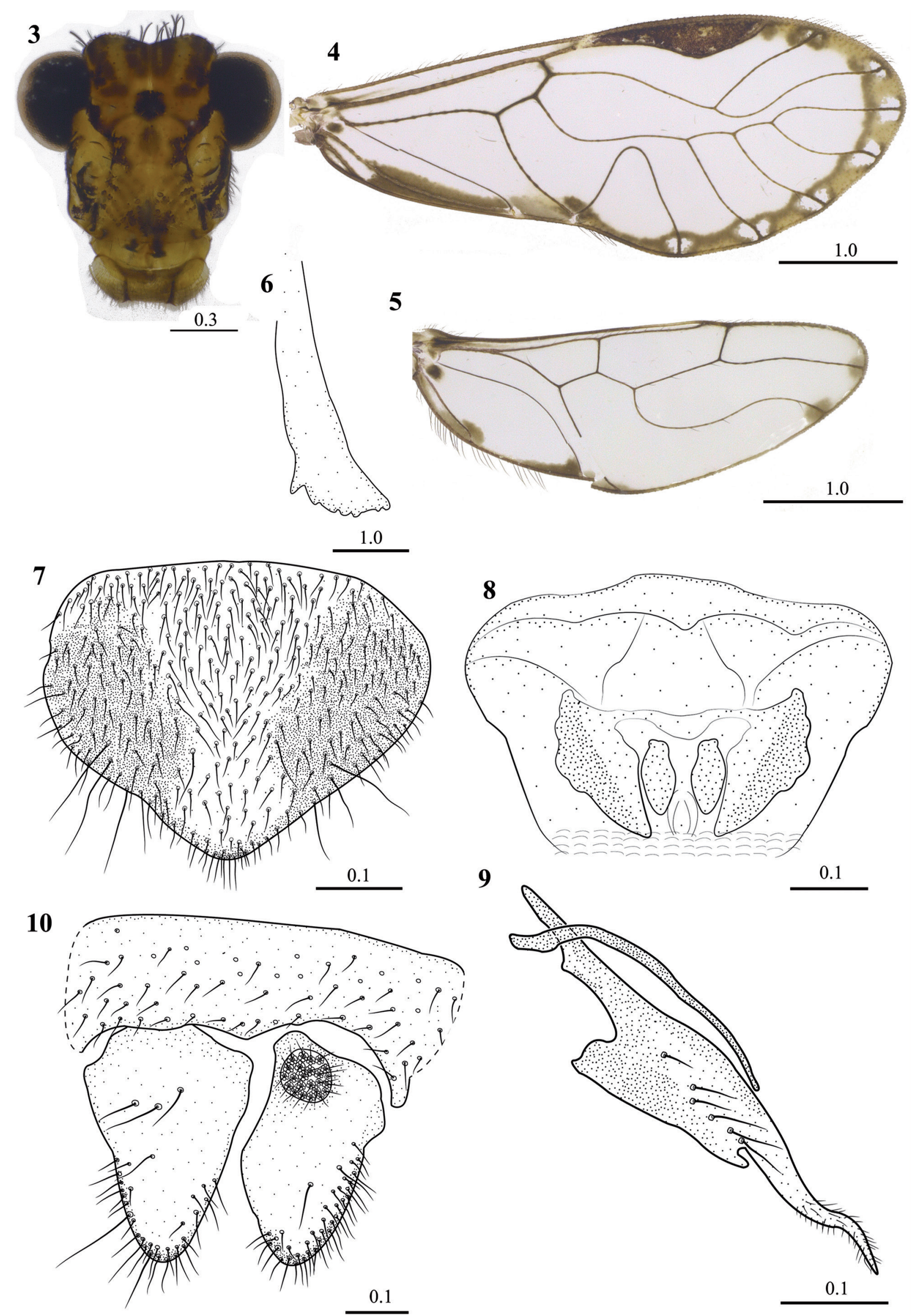

Figures 3-10. Euplocania quinquedivisa. Female. (3) Front view of head. (4) Forewing. (5) Hindwing. (6) Lacinial tip. (7) Subgenital plate. (8) Ninth sternum. (9) Right gonapophyses. (10) Clunium, right paraproct and epiproct. Scales in mm. 
noi González, Carrejo \& Panche and E. rojasae González, Carrejo \& García Aldrete) or half-moon shapes (E. amabilis Enderlein; E. ariasi Vinasco-Mondragón, González \& García Aldrete; E. badonneli New \& Thornton; E. caldasi Vinasco-Mondragón, González \& García Aldrete; E. ecuatoriana Vinasco-Mondragón, González \& García Aldrete; E. equorum Vinasco-Mondragón, González \& García Aldrete; E. gaitanae González, García Aldrete \& Carrejo; E. katios Vinasco-Mondragón, González \& García Aldrete; E. lasdelicias Vinasco-Mondragón, González \& García Aldrete; E. manausensis VinascoMondragón, González \& García Aldrete; E. metensis Vinasco-Mondragón, González \& García Aldrete; E. pictaoides García Aldrete; E. tocantina Mondragón, González \& García Aldrete and E. vaupesiana Vinasco-Mondragón, González \& García Aldrete). In addition to the distinctive pigmentation pattern of the forewing, the female of $E$. quinquedivisa differs from the females of the known species of Euplocania, in details of the ninth sternum (broad, trapeziform, with three distinct areas, posteriorly with sides converging towards a membranous apex) and gonapophyses (with v1 long, slender, heavily sclerotized; v2+3 stout, with short, blunt ended heel, with six setae on $\mathrm{v} 3$ ).

All specimens of $E$. quinquedivisa were collected through the Rede Bionorte: Biodiversidade de insetos na Amazônia project, which was active from August/2017 to October/2018. During this period, five Malaise traps were set in five different heights (ground level, $8 \mathrm{~m}$ above ground level, $16 \mathrm{~m}, 24 \mathrm{~m}$ and $32 \mathrm{~m}$ ) on a tower located in the Amazonian forest, in an area owned by the Reserva Biológica do Cueiras (ZF-2). Interestingly, two male specimens were collected at $16 \mathrm{~m}$ high whilst the female specimen was collected at $8 \mathrm{~m}$ high. Probably, the $8-16 \mathrm{~m}$ range is the ideal height to collect more specimens of $E$. quinquedivisa, therefore revealing that the traditional ground-level Malaise is inefficient to target this species.

The only known specimen of Euplocania xavieri SilvaNeto, García Aldrete \& Rafael was also collected in this tower, at $16 \mathrm{~m}$ high and no other specimen of this species was found during the collection period mentioned above.

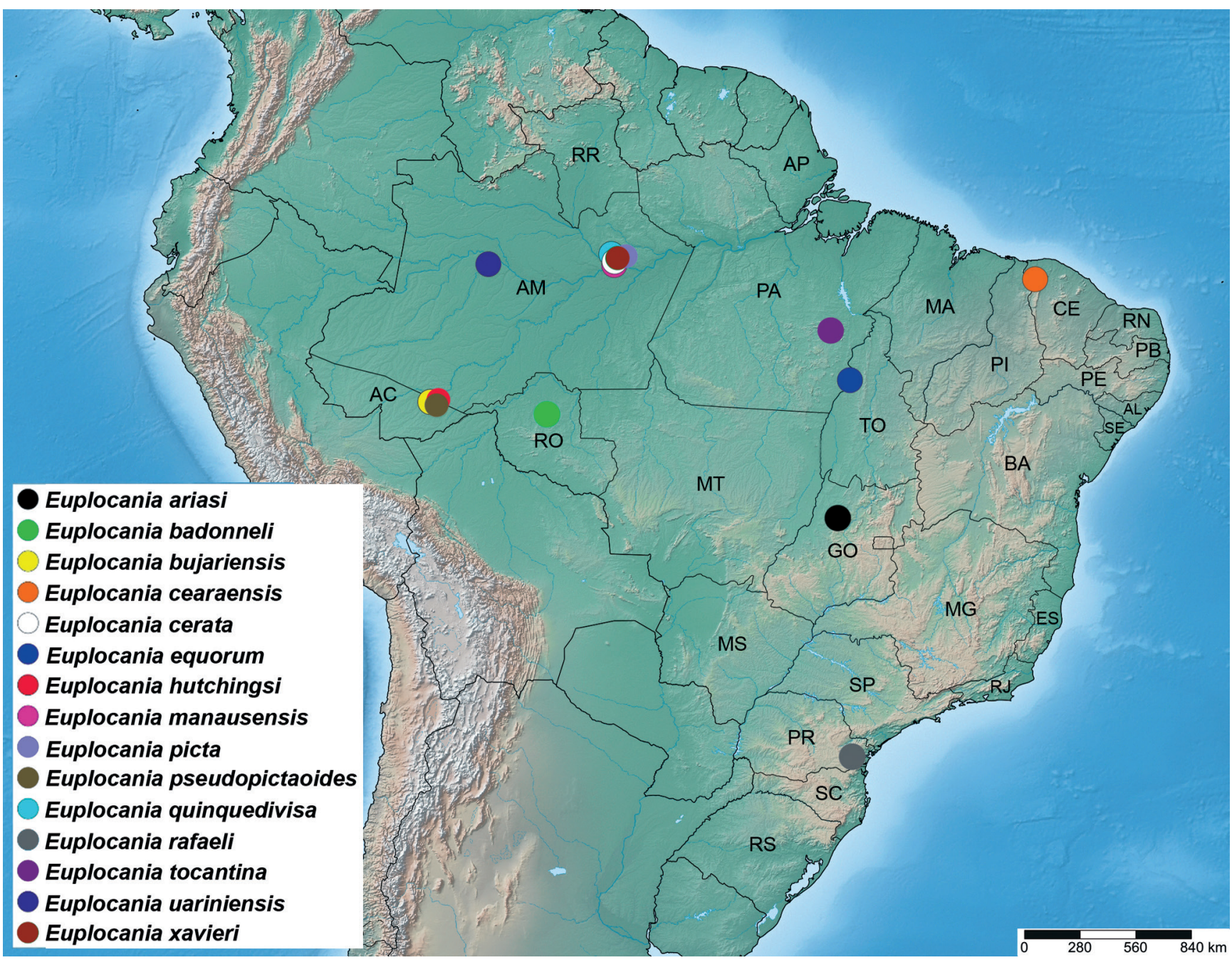

Figure 11. Distribution of Brazilian species of Euplocania in Brazilian states. Abbreviations: $A C=A c r e, A M=A$ mazonas, $R R=$ Roraima, $R 0=R$ nondônia, $A P=A m a p a ́$, $\mathrm{PA}=$ Pará, $\mathrm{MT}=$ Mato Grosso, $\mathrm{MS}=$ Mato Grosso do Sul, $\mathrm{TO}=$ Tocantis, $\mathrm{MA}=$ Maranhão, $\mathrm{GO}=$ Goiás, $\mathrm{PI}=$ Piauí, $\mathrm{CE}=$ Ceará, $\mathrm{RN}=$ Rio Grande do Norte, $\mathrm{PB}=$ Paraíba, $\mathrm{PE}=$ Pernambuco, $\mathrm{AL}=$ Alagoas, $\mathrm{SE}=$ Sergipe, $\mathrm{BA}=$ Bahia, $\mathrm{MG}=$ Minas Gerais, $\mathrm{ES}=$ Espírito Santo, $\mathrm{RJ}=$ Rio de Janeiro, $\mathrm{SP}=\mathrm{São}$ Paulo, $\mathrm{PR}=\mathrm{Paraná}, \mathrm{SC}=\mathrm{Santa}$ Catarina and RS $=$ Rio Grande do Sul. 


\section{ACKNOWLEDGMENTS}

KAB, AMSN and JAR thanks Instituto Nacional de Pesquisas da Amazônia (INPA) and Conselho Nacional de Desenvolvimento Científico e Tecnológico of Brazil (CNPq) for research support. KAB thanks particularly the support for the Pibic-Cnpq research grant (SEl Process: 01280.001061/2019-76). AMSN thanks particularly the support for the PNPD Capes-INPA research grant (Process: 88887.312051/2018-00). JAR thanks particularly the support for the Cnpq research grant (Process: 300.997/2016-7). ANGA thanks Instituto de Biología, Universidad Nacional Autónoma de México, for continuous research support. We also thank the Project Rede Bionorte: Biodiversidade de insetos na Amazônia.

\section{REFERENCES}

Enderlein, G. 1910. Eine Dekade neuer Copeognathengattungen. Sitzungsbericht der Gesellschaft naturforschender Freunde zu Berlin, 2: 63-77.

García Aldrete, A.N.; González, R. \& Carrejo, N.S. 2013. A new species of Euplocania Enderlein (Psocodea: 'Psocoptera': Ptiloneuridae), from Magdalena, Colombia, with a proposed classification of the genus. Dugesiana, 20(2): 149-156.

Silva-Neto, A.M.; García Aldrete, A.N. \& Rafael, J.A. 2016. A Storage Method for "Psocoptera" (Insecta: Psocodea) in "CD Box". Entomobrasilis, 9: 220-223.

Silva-Neto, A.M.; García Aldrete, A.N. \& Rafael, J.A. 2019. New species of Euplocania Enderlein (Psocodea,'Psocoptera', Ptiloneuridae) from Brazil, with a checklist of all known species of the genus. Zootaxa, 4550(3): 374-390. 